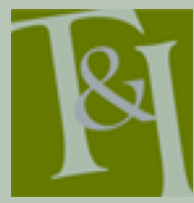

The International Journal for Translation \& Interpreting Research

trans-int.org

\title{
Exploring signed language interpreters' perceptions of e-professionalism on Facebook
}

\author{
Brett Best \\ Independent Researcher, UK \\ brett@bestvisualinterpreting.co.uk
}

DOI: $10.12807 /$ ti.111201.2019.a04

\begin{abstract}
This is an exploratory inquiry into signed language interpreters' perceptions of interpreter e-professionalism on social media, specifically Facebook. Given the global pervasiveness of Facebook, this study presents an international perspective, and reports on findings of focus groups held with a total of 12 professional signed language interpreters from the United States of America, the United Kingdom, and Denmark, all of whom are also Facebook users. The findings reveal that Facebook is seen to blur the traditional boundaries between personal and professional realms - an overlap which is perceived to be compounded by the nature of the small community in which signed language interpreters typically work -necessitating boundary management strategies in order to maintain perceptions of professionalism on the site. Facebook is considered a valuable professional resource to leverage for networking, professional development, problem solving and assignment preparation, but it is also perceived as a potential professional liability for both individual interpreters and the profession at large. Maintaining client confidentiality was found to be the most pressing challenge Facebook brings to the profession. Educational measures to raise awareness about e-professionalism were generally viewed favourably.
\end{abstract}

Keywords: e-professionalism, Facebook, professionalism, ethics, social media, social networking, sign language interpreters

\section{Introduction}

Facebook was chosen as the target platform for this exploratory inquiry into interpreter e-professionalism on social media because it is the world's largest social networking site both in terms of active users and the number of countries in which it is used (The Statistics Portal, 2015). Additionally, the site is expected to continue to grow as mobile device technology increasingly expedites access (Duggan et al., 2015b). Facebook is a globally growing phenomenon, and the properties of this digital domain enable the potential for posts to quickly reach a very wide audience in a very short amount of time. Moreover, posts may be searchable and are replicable via 'shares' and screen shots. It is, therefore, especially important to begin to explore how this pervasive new technology may be bringing new opportunities and challenges to the interpreting profession. An enhanced understanding of how this technology may be impacting the signed language interpreting profession may enable practitioners, clients, educators and other stakeholders to more proactively shape professional usage. This study aims to glean further insight into how signed language interpreters perceive and manage e-professionalism on Facebook and how the site can be used for professional purposes. (This article reports on findings related to general e-professionalism; for a report on findings from the same research group specifically related to the e- 
professionalism consideration of promotion on Facebook, please see Best, 2017).

\section{E-professionalism}

E-professionalism refers to an expansion of the traditional professionalism paradigm to encompass the digital realm (Cain \& Romanelli, 2009). Information available online and via one's online persona are considered to fall within the purview of e-professionalism, and such information often may have originated in personal settings before being rendered public in the online environment (Cain \& Romanelli, 2009). In addition to public viewability of information, other considerations include the potential for online information to very quickly reach a large number of people, easy replication of online content, and the permanency of online material due to its digital trail. Hence the impacts of online indiscretions are amplified considerably more so than in traditional face-to-face settings (Greysen, Kind, \& Chretien, 2010). These unique properties of the online domain have potential repercussions for both individual professionals as well as the profession at large, since an individual may be perceived as representing an entire professional group (Cain \& Romanelli, 2009). Spector et al. (2010) report that e-professionalism considerations often manifest through social networking sites such as Facebook and that, furthermore, the relatively recent appearance and proliferation of such sites mean that considerations of e-professionalism are only beginning to be acknowledged.

Best (2016) points out that the bulk of existing research into eprofessionalism has been done within the medical profession and that interpreting - like the field of medicine - is a practice profession (Dean \& Pollard, 2013). Hence interpreters may find the existing research into eprofessionalism particularly applicable. Another parallel between the medical and interpreting fields in regards to e-professionalism is that individuals and authoritative bodies from both fields have made calls for education and awareness-raising on professional social media usage (HINTS, 2011; Kaczmarczyk et al., 2013; Spector et al.; 2010).

\subsection{E-professionalism on Facebook}

Whilst some studies have identified professional benefits of Facebook such as continuing professional development and professional networking opportunities (Lawson \& Cowling, 2015; Weber \& Vincent, 2014), much of the existing e-professionalism research on Facebook has focused on potential dangers and drawbacks rather than potential benefits. Several studies have surveyed specific demographics such as medical students and medical professionals for markers of unprofessionalism on Facebook profiles (Cain, Scott \& Akers, 2009; Clyde, Rodriguez \& Geiser, 2014; Lagenfeld et al., 2014; Lee \& Ho, 2011; Ponce et al., 2013; Walton, White \& Ross, 2015). A challenge for researchers, however, seems to be defining the boundaries of unprofessional content. Conspicuous infractions such as evidence of binge drinking or sexually suggestive photos and blatant breaches of client confidentiality are generally acknowledged as unprofessional, but beyond these boundaries, what constitutes unprofessional behaviour has been found to be largely subjective (Chretien et al., 2010; Lagenfeld et al., 2014).

In addition to the type of content posted, it is also important to consider the audience that may be able to view a post. This is important because certain groups may interpret certain content differently. Basic privacy measures, such as setting public viewing restrictions on posted content, may not be sufficient. On Facebook, people may connect with one another by sending and accepting friend requests, and this typically gives users greater access to one another's 
content. A post that is not visible publicly may still be visible to all of an individual's online friends, many of whom may comprise different audience groups. This may lead to something known as 'context collapse' - a term used to refer to a potentially infinite audience online, and the difficulty of managing context separation when several online friends from diverse life contexts are grouped into a single location (Wesch, 2008). Context collapse occurs when a post is made with a certain group in mind but several online friends from outside of the intended target audience are also able to view the post. Moreover, those for whom the post was intended may not even see it (Sibona \& Walczak, 2014; see also Marwick \& Boyd, 2011 as cited in Wendorf \& Yang, 2015). Considerations of context collapse contribute to the complex nature of how posts may be perceived on Facebook (Utz, 2014).

An additional consideration impacting e-professionalism is the nature of online friendships.

Researchers Lewis and West (2009) found that "friending" on Facebook often flattens many types of connections into the single category of 'friend.' Hence many Facebook friendships are typified as weak, low-commitment connections (Lewis \& West, 2009). This is illustrated by findings of the Pew Research Report which found that of those surveyed, 39\% of respondents reported being Facebook friends with someone that they had never met in person; furthermore, when asked to approximate how many of their Facebook friends were actual friends, the median number given was 50 (out of a median number of 155 total Facebook friends) (Duggan et al., 2015a).

Strategies for managing factors such as context collapse may include posting either only professional or only personal content on certain designated Facebook accounts or in specific groups. Research, however, suggests that this approach may have unintended ramifications as well. For example, disclosing some personal information on one's profile - as opposed to only professional information - has been found to actually enhance perceptions of professionalism and credibility (Cylde, Rodriguez \& Geiser, 2014; Mazer, Murphy, \& Simonds, 2009). Some personal disclosure seems to allow enough information for others to form a determination about an individual's character as a person (Cylde, Rodriguez \& Geiser, 2014).

Another challenge for broadly fostering e-professionalism is that research has found that it is not possible to identify who may be at risk for posting unprofessional content (Ponce et al., 2013). Furthermore, Lagenfeld et al. (2014) found that the posting of unprofessional content on Facebook did not decrease as medical students progressed through their training, which they suggest indicates a gap in the educational curricula. The mention of curricula is important as researchers report that simply raising awareness via explicit instruction is effective in fostering greater e-professionalism (Cain et al., 2009; Lee \& Ho, 2011; Walton et al., 2015).

\subsection{Interpreters and e-professionalism}

There is seemingly no research at present addressing interpreter eprofessionalism, but there exists published material discussing social media use by interpreters as well as general social media guidelines specific to interpreters. Whilst the existing materials are not based in academic research, as a nascent area of study in the interpreting field, it is relevant to acknowledge these published materials to evidence that interpreter eprofessionalism is an area worthy of research and academic inquiry.

Applicable to both spoken and signed language interpreters is the 2011 Declaration on the use of social media, issued by the Heads of Interpreting Services (HINTS) of major international institutions, which contains general observations and principles for social media usage by professional conference interpreters. The Declaration was also disseminated by the International Association of Conference Interpreters (AIIC) via a link in an item 
(Recommendations on social media issued by Heads of Interpreting Services) in the Association's Interpreting News webzine (AIIC, 2012, April 4), where it is described as "guidelines for the use of social media by interpreters" (para.1). The HINTS Declaration specifically mentions Facebook, and while it acknowledges that social networking platforms such as Facebook "can be used in a positive sense to raise awareness about the profession and to attract young people to interpretation studies," (HINTS, 2011, par. 3) the main focus is on averting the potential risks of interpreters using these sites. As the document warns, "if not properly used, [these platforms] can also adversely affect the perception of the profession" (HINTS, 2011, par. 4).

According to AIIC's brief news summary (2012, April 4), the Declaration emphasises "maintaining confidentiality and using common sense" (par.1); the HINTS Declaration itself considers common sense to be the most important of the "generally accepted guiding principles" (2011, par. 7). However, the premise of relying on common sense as a guiding notion for professional behaviour online has been contended in the literature. Best (2016) points to research indicating the emergence of an online culture and new norms for information disclosure among millennials (Anderson \& Rainie, 2010) and argues that differing online norms amongst user groups may make a reliance on common sense ineffective in fostering desired online professional behaviour across all demographics. A study done by Chretien, Goldman, Beckman, and Kind (2010) does seem to suggest that some social media users may experience some uncertainty when relying entirely on common sense. These researchers reported that whilst medical students relied on common sense to guide their posts, these same students also expressed a desire for recommendations and further discussion to raise awareness about appropriate content (Chretien et al., 2010).

The type of recommendations and awareness-raising that were indicated as desirable by medical students in the Chretien et al. (2010) study are essentially what the HINTS Declaration aims to promote for interpreters. It also called on interpreter training programs, professional associations, and employers of interpreters to use explicit references to professional social media usage when addressing appropriate online conduct and professional ethics (HINTS, 2011, par. 6). Some employers of interpreters such as interpreting provision agencies have answered this call by providing their own social media guidelines (DAS, 2015).

Specifically related to signed language interpreters, there have been some blog posts that address social media use, and the World Association of Sign Language Interpreters (WASLI) published a special edition newsletter dedicated to the topic which sought opinions and perspectives from practitioners (WASLI, 2016). One blog for Auslan/English interpreters generated interesting discussion when Judd (2015) raised questions regarding the professional appropriateness of posts she had observed on Facebook, including interpreters posting:

- assignment locations or travel plans to an assignment,

- commenting on and/or sharing experiences about what happened at an interpreted event

- making emotive connotations related to interpreting assignments being cancelled or finishing early

- disclosing that they had interpreted for high-profile Deaf people after said person had passed away

It is important to note that the Codes of Professional Conduct for signed language interpreters for the U.S. and U.K. do not explicitly mention eprofessionalism. According to focus group participants, Denmark does not have a formal, written code of ethics. Instead, ethical values are taught during 
interpreter training. There has, however, been a call from one American author to implement specific reference to e-professionalism into the United States Registry of Interpreters for the Deaf (RID) Code of Professional Conduct (CPC) for American Sign Language (ASL)/English interpreters (Butler, 2012). On the American blog www.streetleverage.com, Butler (2012) reviews what he perceives to be problems on social media sites like Facebook which lead to what he refers to as ethical distortions by signed language interpreters. Butler (2012) suggests that the problems are so pronounced that a new tenet is needed in the CPC. However, Best (2016) argues that eprofessionalism is based on the values of traditional professionalism already enshrined in the Code, so an entirely new tenet in the CPC for the online domain is unnecessary and would be redundant. Relatedly, Watson et al. (2015) explain that instituting hard rules for Facebook is challenging due to evolving technology, thus making guidelines necessarily vague and creating a need to defer to professional judgment. This is a reality which, the authors argue, strengthens the case for incorporating specific curricula for eprofessionalism into training programs.

\subsubsection{Small world ethics}

The signed language interpreting profession may offer a unique case in regards to e-professionalism due to a prevalence of overlapping affiliations (Best, 2016). This argument is based on Lannin and Scott's (2013) suggestion that social media creates a small world environment with several overlapping relationships. Whilst researchers report that personal and professional identities converge on social media (Ollier-Malaterre, Rothbard, \& Berg, 2013; Ramarjan \& Reid, 2013), Lannin and Scott (2013) contend that ethical nuances from overlapping spheres of life need not become unmanageable. The authors point to rural psychologists and contend that these professionals have been practicing in such small world environments for decades, and they suggest that modern professionals can look to the strategies utilised by these rural psychologists to learn how to navigate the overlapping relationships and hence small world ethics of social media (Lannin \& Scott, 2013).

Best (2016) contends that signed language interpreters may already be similar to rural psychologists due to the fact that the Deaf community is very small, and signed language interpreters may either have Deaf family members or friendships with those in the Deaf community. This potentially creates a metaphorically smaller world environment on social media, fundamentally changing how a signed language interpreter would need to practice such small world ethics (Best, 2016). A comment submitted by an interpreter from Canada in the recent WASLI (2016, p.8) newsletter dedicated to the topic of social media lends credence to this possibility: "[I]n my IEP we had many community hours volunteer interpreting or simply socializing to develop our language. A common refrain after saying goodbye after these interactions became, 'Are you on FB?'” Hence whilst Butler (2012) suggests that signed language interpreters keep separate personal and professional realms, Best (2016) posits that bifurcation may prove murky for some signed language interpreters due to overlapping relationships. As Ollier-Malaterre et al. (2013, p. 645) acknowledge, the convergence of personal and professional domains online leads to "new opportunities and challenges for boundary management and identity negotiation in cyberspace." This may prove especially true for professionals who were already working in small communities prior to the advent of social media such as Facebook.

\section{Methodology}

This study was qualitative and based on three focus groups, each lasting 
between 60-80 minutes with a total of 12 interpreters. Wilson, Gosling and Graham (2012) state that there is uncertainty about the most effective ways to do Facebook research since it is still a fairly recent phenomenon. For this study on interpreter perceptions of Facebook e-professionalism, focus groups were chosen to begin probing practitioner perspectives.

International perspectives were sought due to the global nature of Facebook. Focus groups were held with interpreters from the following three countries: United States of America; the United Kingdom; Denmark. Each focus group consisted of 4 interpreters. Requisites for participation were that an individual be a signed language interpreter, a Facebook user and proficient in spoken English. (It is important to note that English is not an official language of Denmark, so expressions made by those in the Danish group were not conveyed in their native language.) A Facebook user was defined as someone currently signed up to Facebook and using the site. Participants were chosen if they satisfied the qualification criteria. For example, some individuals expressed interest in participating in the study but had previously closed their Facebook accounts. They therefore did not qualify since they were not current users of the site. It was deemed important to have current Facebook users so that participants could report on what they were presently observing.

Calls for participants were disseminated via email to professional networks and by Facebook posts set to public viewing. Each country group was specifically targeted, so separate calls were put forth for signed language interpreters in the U.S.A., U.K. and Denmark. This ensured an international perspective whilst also allowing for feasible logistics to schedule Skype focus groups with regard to international time differences. It also enabled the possibility to identify country-specific differences based on national contexts, which may have been more difficult to discern in mixed groups of nationalities.

Participants filled in a consent form to participate in the study and confirming that they understood their responses and participation would be anonymised. They were not paid for their involvement. Participants also filled in a basic data form asking demographic information and questions about their Facebook profile such as whether or not they were Facebook friends with other interpreters, Facebook friends with clients, and how often they logged into the site.

Focus groups were held via Skype to facilitate the international aspect of the study. The researcher ran all three focus groups to ensure consistency of moderation and following focus group protocol put forth by Gibbs (1997) and Napier and Hale (2013). Several semi-structured prompt questions about observations of Facebook usage were asked to guide discussion of practitioner perspectives. Leaving the discussions open to observations of others as well as personal anecdotes when voluntarily offered allowed the conversations to flow smoothly with the possibility of drawing out the most information possible. Prompt questions addressed broad topics identified in the literature such as personal versus professional online persona (Cain \& Romanelli, 2009; Butler, 2012; Cylde et al., 2014) and relationships on Facebook (Lewis \& West, 2009; Lannin \& Scott, 2013). Some specific prompt questions included:

- What are some ways that you see your interpreter colleagues using Facebook?

- What are some of the benefits that Facebook has brought to the profession?

- What are some of the challenges that Facebook has brought to the profession? and

- Do you think that there needs to be any kind of education or training either in ITPs or workshops on how to professionally use sites such as 
Facebook, or do you think that it is sufficient to expect professional usage to be naturally acquired?

The focus group sessions were recorded and then transcribed verbatim. These transcriptions were then uploaded to QSR International's NVivo 10 qualitative data analysis computer software, which facilitated the "scissor-andsort technique" (Stewart, Shamdasani, \& Rook, 2006) to aid in the identification of a thematic framework (Rabiee, 2004) for identification of major issues and topics. A content designation analysis (Stewart et al., 2006) was performed for frequent words indicating or relating to prominent themes. In this approach, the number of times that a specific word or concept is mentioned is counted in order to determine its saliency.

Themes were identified as topics directly relating to the literature and/or topics that at least two groups mentioned. In this way, topics mentioned by at least two groups became a theme which was either supported by the literature or became a theme revealed by the research that was not mentioned in the literature. Whilst overarching themes were identified and coded accordingly, attention was also directed toward identifying any country-specific themes by expressed relevancy or irrelevancy or by noting when one group (country) did or did not address a specific theme.

\subsection{Participants}

Eleven of the twelve participants returned forms asking for basic participant information. Four of the participants were in the age range of 26-33; four were ages 34-41, and three were ages $42-49$. Ten of the twelve participants were female, and two were male. All were active users of Facebook, with three signing into Facebook daily and eight logging into Facebook more than once a day. All focus group participants who submitted data forms were Facebook friends with other signed language interpreters, and all were Facebook friends with deaf people or those with ties to the Deaf Community. Nine were Facebook friends with clients; one was Facebook friends with past clients but not current clients; one was not Facebook friends with any clients.

\section{Results and discussion}

Participants reported their own experiences using Facebook, posts made by others on the site that they had witnessed and strategies they personally used when making a post. This research did not identify any patterns related to how often a participant logged into Facebook and what they reported in the focus groups.

Table 1: Themes and sub-themes

\begin{tabular}{l}
\hline Themes and Sub-themes \\
1. Boundary management \\
Personal versus professional space \\
Public versus professional space \\
2. Confidentiality \\
3. Professional benefits \\
4. E-professionalism education \\
\hline Common sense ethics \\
\hline
\end{tabular}


As Table 1 above shows, four prominent themes emerged from the focus groups, two of which had sub-themes: Boundary management with the subthemes of personal versus professional space and public space versus professional space; confidentiality; professional benefits of Facebook; and perspectives on the need for e-professionalism education with the sub-theme of common sense ethics.

\subsection{Boundary management}

The theme of boundary management and the sub-theme of public space versus professional space were identified via significant discussion on the subjects by all three groups. The sub-theme of personal versus professional online personas was discussed by all three groups and is supported in the literature (Clyde et al., 2014; Butler, 2012; Lannin \& Scott, 2013).

Focus group contributors reported self-monitoring of posts and exercising reserve with certain opinions or content as a way to manage perceptions of their professionalism on Facebook, regardless of any personal and professional overlap. Whilst it was agreed that this overlap of realms on Facebook offers challenges such as maintaining professional boundaries, there were several expressed advantages (discussed in the professional benefits section below).

\subsubsection{Personal versus professional space}

During focus group discussion, all of the participants reported being Facebook friends with other interpreters and members of the Deaf Community. A prevailing view that surfaced is that signed language interpreting may be different than other professions due to relationship overlap through involvement in the Deaf Community, as Participant 10 from the British group explained:

I think there's an overlap [between personal and professional personas] because of how it's not a 9 to 5 job. It's a community we're involved in, so we do have Deaf friends as well as clients and colleagues.

Participant 9 from the British group remarked:

[O]ften our social lives are so inter-tangled with our professional lives. I know that a lot of my friends are interpreters so we're out with interpreters or we are out with Deaf people because our lives are so intertwined.....our personal and professional identities become so blurred.

None of the interpreters in this study had separate personal and professional profiles in which separate Facebook accounts were dedicated solely to personal or professional types of posts. Research has found that personal and professional spheres often converge on social networking sites for many professionals (Ollier-Malaterre et al., 2013; Ramarjan \& Reid, 2013). The sentiments expressed by these focus group participants align with these findings and may offer support for theories such as Best's (2016) argument that signed language interpreters may often be functioning in small world ethical environments prior to logging onto social media such as Facebook.

\subsubsection{Public versus professional space}

Whilst the boundaries between personal and professional domains seemed to overlap for interpreters in these focus groups, participants did report intentionally drawing a boundary between public space and professional space. A common strategy for managing context collapse (Sibona \& Walczak, 2014, as cited in Wendorf \& Yang, 2015) and potential ensuing perceptions of the professional and the profession was to only post certain content, questions 
or conversations within specified groups of fellow practitioners rather than on one's general Facebook page. Examples given by participants of content that should be posted in designated groups included discussion on fees, interpreters looking for job cover and queries regarding what to do when facing a workplace dilemma. This posting strategy makes certain content unavailable to those Facebook friends who had not been included in the Facebook group. Not only were these types of groups reported as useful for networking and support among interpreters, they were also seen to be of instrumental importance for maintaining a positive public image of the profession at large.

\subsection{Confidentiality}

Confidentiality was not mentioned in any prompt questions by the researcher, but all three groups discussed it. This discussion by all three groups identified confidentiality as a theme. Participants reported seeing posts which they felt either breached confidentiality or fell into a grey area of professional acceptability. This theme is supported by the literature in that the Code of Professional Conduct for the U.S. and the U.K. explicitly mention confidentiality. The Danish interpreters stated that although there is not a formal, written code of conduct for signed language interpreters in their country, the primary ethical tenet taught during interpreter training is confidentiality.

The issue of confidentiality appeared as a particularly salient theme and the top challenge that participants felt Facebook brought to the profession. In the content designation analysis (Stewart et al., 2006), the word 'confidentiality' was mentioned 39 times and the word 'confidential' 4 times. This resulted in a total of 43 explicit references to the issue of keeping information regarding assignments confidential. In comparison, the more encompassing word 'ethics' was distinctly mentioned 10 times, and 'professionalism' was only explicated 7 times.

Focus groups revealed that all participants unanimously agreed that violations of confidentially on Facebook were unethical and therefore unprofessional. Differences in perceptions arose, however, when determining what - or at what point - something was perceived as violating confidentiality. Participants expressed a common position that confidentiality was largely inapplicable to large public events. (For further information see Best, 2017).

There was also consensus that certain types of posts were problematic. Location check-ins or mentions of a specific location in a post were viewed as presenting ethical dilemmas. Participants explained that deductive disclosure was possible within a small community such as the Deaf Community, thereby making possible a greater divulgence of potentially identifying information than what the actual words of the post may have said or intended. As Participant 1 in the American group explained:

I think that the ones [posts] I see that are more insidious are when people are checking in. They don't even think about the check in....Well, now I know where you are working because I know that there are three deaf people that work in that three block radius...people don't realise how people can put the pieces together.

As Participant 12 in the British group stated:

I've seen plenty of stuff where I'm thinking I might not have said that. Down to stuff like pronouns. I have seen people post things of every shade of gray, from right down to, "I can make a really good $90 \%$ guess of who you were working with today" to more subtle things.

All focus groups discussed examples illustrating the possibility for the unintended divulgence of identifying information due to the ability of those 
familiar with the community to make certain inferences. The Danish group discussed how pictures did not necessarily need to be of a person in order to potentially impact on considerations of small world ethics by revealing identifying details but, as Participant 6 explained, just a picture of a monument or a statue taken whilst interpreting in a foreign locale, for example, could provide information about whom an interpreter was working for and on what assignment.

These statements explaining the perceived problems for confidentiality resulting from location check-ins, other location disclosures or assignment information support the saliency of concepts in the literature such as small world ethics of small communities (Lannin \& Scott, 2013) made metaphorically even smaller in an online environment such as Facebook (Best, 2016). Judd (2015) raised questions regarding the appropriateness of signed language interpreters posting about the locations of assignments or travel plans to an assignment. These questions seem to be answered by the fact that all focus groups mentioned the need to raise awareness and exercise care when posting any assignment-related information due to the small community in which signed language interpreters work and the ensuing ability of members of the community to make knowledgeable inferences regarding clients.

\subsection{Professional benefits}

The theme of professional benefits was discussed by all three groups. This theme is also supported in the literature which profess the professional advantages of social media sites such as Facebook (Lagenfeld et al., 2013; Weber \& Vincent, 2014; Lawson and Cowling, 2015), namely facilitated communication and networking with colleagues and opportunities for professional development.

The benefits that Facebook offers the profession were explicitly perceived by all participants to outweigh the challenges. The greatest professional benefits expressed centred around the increased connection that Facebook offers, both in terms of numbers of people and speed of information delivery. All groups articulated the importance of Facebook for becoming aware of events in the Deaf and interpreting communities and for staying upto-date on relevant topics. Participants explained that their professional development was facilitated through Facebook as a great deal of professional literature, research, issues, and conference or workshop opportunities are readily available and widely disseminated through Facebook. The ability to quickly discuss these topics with a broad range of colleagues around the globe was seen to enhance professional learning opportunities as well.

Another benefit was an enhanced ability to identify suitable interpreters for specific assignments based on knowledge about fellow colleagues gleaned from their Facebook page. The American group, as an illustration, discussed instances of being able to identify suitable interpreters for specific assignments - a quilting class or a Jewish event were given as examples based on knowledge about fellow interpreters' interests, skills, or background mentioned on their Facebook page. Similarly, participants from all groups spoke of finding Facebook very useful for assignment preparation by searching for their co-interpreters and/or the Deaf client in order to learn more about them and to gain insight into recent events, names or topics of interest that could feasibly come up during the course of the assignment. Facebook was also said to be useful for language samples. Some participants reported using Facebook to view posted videos that might provide insight into the client's signing style. Danish Participant 5, for example, relayed how Facebook-facilitated assignment preparation can help with knowing how to fingerspell names that may be mentioned in discussion. It was also cited as useful in helping interpreters identify co-workers or clients at an assignment 
by allowing them to put a face to a name beforehand.

It could be argued that interpreters having more access to information of relevant individuals as well as to more professional development information could improve their professional performance and thereby confer a benefit to clients. This study additionally identified more direct and immediate examples of how interpreters using Facebook could benefit clients. Participants reported the ability to ask the Facebook community for certain signs and quickly receive posted videos demonstrating the correct production of the sign, which was believed to be much quicker and clearer than asking a few people via direct personal correspondence - such as text - and attempting to discern the correct sign production from a written explanation. Similarly, one American interpreter, Participant 1, explained the usefulness of being able to tap into the resource of the Facebook community:

[It's good] when you are trying to signal boost or crowd source to use the internet hive mind to solve a problem or come up with a solution. We had a deaf kid from Peru so asked 'Does anyone know Peruvian Sign Language?' We were able to work out a solution because I was able to put it on Facebook and just ask everybody, and it expands all of my contacts all over the globe.

Professional networking of this type as well as other kinds was frequently cited as important. Many people mentioned the use of interpreting groups on Facebook for both interpreters and interpreting students dedicated to relevant issues and as a forum in which to ask questions and have conversations related to interpreting matters. These Facebook groups were reported to make participants feel both more deeply connected and more frequently connected to those in the profession in comparison to the opportunities for connection offline only at biannual conferences, occasional workshops, or sporadically at co-working jobs. British Participant 12 reported going off Facebook for some time before re-joining due to a feeling of "missing out" on what colleagues and others were doing, offering further testimony to the amount of general activity and professionally relevant information that is shared on the site.

\section{4 e-Professionalism education}

The researcher asked a prompt question regarding the perceived need for eprofessionalism training. Perspectives on the need for e-professionalism education is a theme drawn from the literature reporting that such targeted education has been beneficial for medical students (Cain et al., 2009; Lee \& Ho, 2011; Walton et al., 2015) and calls from both medical and interpreting bodies for such education (HINTS, 2011; Kaczmarczyk et al., 2013; Spector et al.; 2010). The sub-theme of Common Sense Ethics was identified by discussion in two groups and is also mentioned in the literature (HINTS, 2011; Best, 2016).

When asked about the need for specific e-professionalism education, all participants eventually agreed that awareness-raising measures may be useful - or at the least, that such initiatives would not be detrimental. There were, however, initially mixed perspectives from the Danish and British groups concerning the necessity of such education. The American group strongly supported training and awareness-raising through general e-professionalism education, as summed up in a comment made by Participant 1:

I think it's part of the larger conversation about your persona, about what you project professionally. That is the training component that is sorely lacking in our ITPs and never very present in our workshop offerings....Especially nowadays with all different forms of social media that's available, how everything is increasingly electronic. Being able to develop a digital portfolio that includes your social media presence is an important part of being a professional interpreter. 
Interestingly, Danish Participant 5 had recently graduated from an interpreter training program and responded that she had one lesson in which the teacher spoke about how to handle social media, particularly in regard to confidentiality. This lesson did not teach what to do or what not to do but was instead intended to raise the students' awareness. Participant 5 explained that she found this lesson helpful:

Because at least at that point I hadn't even thought about it at all. I hadn't thought of it as an issue. When she brought it up I realised that, of course, it's an issue. You have to at least think about what you do. Not that there's a straight answer to what you should put out there or what you shouldn't or who you should friend, but as long as you are thinking about it and can argue for or against why you are doing something.

The Danish group also reported a perceived increase in general awareness among interpreters in their country resulting in fewer posts that were viewed as unprofessional. As Danish Participant 8 stated, and with which other group members concurred:

I see a different picture now than I did before. In the beginning people didn't think much about what they were posting on Facebook, but I think it's changed now.

This is noteworthy because not only did the Danish group have the sole participant who reported having received specific instruction in eprofessionalism, the Danish participants also explained that the agencies that they worked for had actively fostered awareness on the topic and developed a shared understanding of e-professionalism. This was done by bringing in a consultant to give a talk on social media and encouraging group discussions on the issue to develop shared expectations of appropriate posts for social media such as Facebook.

Research conducted with medical students has found that simply raising awareness through education is of key importance in fostering eprofessionalism (Cain et al., 2009; Lee \& Ho, 2011; Walton et al., 2015). In light of this research, it is interesting that the Danish focus group was the only group to report targeted awareness-raising initiatives and also the only group to report a perceived decrease in unprofessional Facebook posts. It may be worth exploring in more depth if this focus on the topic contributed to the perception that interpreters on Facebook in Denmark are now posting with increased professional conscientiousness.

It may also be the case that small world ethics (Best, 2016; Lannin \& Scott, 2013) arguably facilitate the development of a shared understanding around standard accepted practices. The Danish Deaf and interpreting communities are considerably smaller than their American and British counterparts, thereby giving more opportunities for interaction, discussion and both tacit and explicit agreement on acceptable practices.

\subsubsection{Common sense ethics}

Some participants felt that professional competency with Facebook should be expected. Participant 7 in the Danish group stated that professionalism on Facebook should just be common sense. This was echoed by Danish Participant 6, who felt that people should be "adult enough" to use Facebook in a professional way. These sentiments were further alluded to by British Participant 10 who remarked that once qualified, interpreters should be at a professional level, and in the modern world, this includes Facebook.

The sentiments expressed by some participants that appropriate professional usage of Facebook should simply be expected is in line with the 
HINTS social media declaration (HINTS, 2011), which has as a main guiding principle the use of common sense. Common sense has, however, been called into question as a solid guiding premise (Best, 2016). It is also interesting to note that British Participant 10 stated that professionally appropriate usage of social media should be expected of interpreters by the time they are fully qualified. Research done with medical students, however, found that the posting of unprofessional content did not decrease as students progressed through their training, leading to recommendations that specific education be added to curricula (Lagenfeld et al., 2014).

Whilst e-professionalism education was not viewed as an imperative by all participants, in all groups it was eventually agreed through discussion that some type of awareness-raising would not hurt. Further research specific to the interpreting field could explore the effectiveness of such awareness-raising education in more depth.

\subsection{Study limitations and future research}

This exploratory inquiry into signed language perspectives of eprofessionalism on Facebook has some limitations. First, the sample size for this research study is relatively small. Further research could build upon these findings to analyse perspectives from a larger number of interpreters. Second, this study sought perspectives on Facebook activity, but it could not establish how often different types of activity occurred. For example, although all participants reported having seen posts that they felt breached confidentiality to some extent, when asked how often they saw such posts, responses from participants in the same groups ranged from "often" to "rare." The exception is the Danish group who all reported seeing a decrease in such posts over the years, although this still does not give a definitive indication as to the frequency of these types of posts.

The difference in e-professionalism education and a perceived decrease in unprofessional posts reported by the Danish group was the only difference identified between the three countries. It is worth noting that although this study sought an international perspective, all three countries are Western countries. Further research could delve into whether there are any differences in e-professionalism practices or perceptions in a wider range of geographies.

This study only sought perspectives from signed language interpreters. Future research could seek insight from spoken language interpreters. Another interesting avenue of research would be to look into current interpreting curricula to determine if or how widely e-professionalism is being addressed and, if so, what impact it may have, if any.

\section{Conclusion}

As an exploratory inquiry into perceptions of signed language interpreter eprofessionalism on Facebook, this study identified several issues experienced by practitioners in three different developed areas of the globe: the United States of America, the United Kingdom, and Denmark. Interpreters in this study expressed the belief that the nature of the small community in which signed language interpreters typically work contributes to an enhanced overlap of personal and professional realms on Facebook, an illustration of the theoretical concept of small world ethics (Best, 2016; Lannin \& Scott, 2013). A range of boundary management approaches were explained with all participants agreeing that certain conversations and posts should happen in closed groups of practitioners as opposed to the public forum in order to manage perceptions of the profession and individual practitioners. Confidentiality was identified as the most pressing challenge that Facebook brings to the profession. 
The professional benefits of Facebook were seen to outweigh the potential drawbacks. These advantages included enhanced networking, professional development and assignment preparation. This study also found that there could be a benefit for clients with members of the signed language interpreting profession using Facebook to ask for signed vocabulary or identify interpreters appropriate for specific assignments based on their personal interests and information.

The eventual general consensus within the focus groups in this study was that training in the proper professional usage of social media - and especially under the broader umbrella of maintaining an online professional persona could be useful. It is noteworthy that Denmark, the country in this study which reported the most measures taken toward raising awareness, also reported a perceived general decrease in posts deemed unprofessional over the past few years. Hence interpreter educators may wish to consider incorporating aspects of e-professionalism into traditional ethical discussions.

E-professionalism training could include discussions to raise awareness about possible small world ethics considerations with specific illustrative examples. Discussion topics could focus on implications of checking-in at assignments, posting information about the location or travel to or from an assignment, and any type of information that might allow others familiar with the community to draw inferences about with whom one is working. The benefits of using Facebook to learn vocabulary, network with colleagues and stay up-to-date with training and community events should also be emphasised.

\section{Acknowledgments}

The author gratefully acknowledges the participants of the focus group sessions for their generosity.

\section{References}

AIIC. (2012, April 4). Recommendations on social media issued by Heads of Interpreting Services. Interpreting News (Webzine - March 2012) Retrieved from http://aiic.net/page/3870/recommendations-on-social-media-is\%20sued-byheads-of-interpreting-services/lang/1.

Best, B. A. (2016). E-professionalism and signed language interpreters: Considering social media, online disclosure, and small world ethics. Journal of Interpretation, 25(1), Article 2. Retrieved from http://digitalcommons.unf. edu/joi/vol25/iss $1 / 2$.

Best, B. (2017). 'Look-at-me' versus 'Look-at-this': Signed language interpreters' perceptions of promotion on Facebook. International Journal of Interpreter Education, 9(1). Retrieved from http://www.cit-asl.org/new/signed-languageinterpreters-perceptions-of-promotion-on-facebook/.

Butler, W. (2012). Does social networking impair sign language interpreter ethics? Retrieved from http:/www.streetleverage.com/tag/social-media-policy/.

Cain, J., Scott, D. \& Akers, P. (2009). Student pharmacists' Facebook activity and opinions regarding accountability and e-professionalism. American Journal of Pharmaceutical Education, 73(6), 104.

Cain, J. \& Romanelli, F. (2009). E-professionalism: A new paradigm for a digital age. Currents in Pharmacy Teaching, 1, 66-70.

Chretien, K.C., Goldman, E.F., Beckman, L., \& Kind, T. (2010). It's your own risk: Medical students' perspectives on online professionalism. Academic Medicine, 85 (10), S68-S71. doi: 10.1097/ACM.0b013e3181ed4778.

Clyde, J.W., Rodriguez, M.D., \& Geiser, C. (2014). Medical professionalism: An experimental look at physicians' Facebook profiles. Medical Education Online, 19.

Deaf Access Solutions (DAS) (2015). Social media guidelines. Deaf Access Solutions, Washington, DC.

Duggan, M., Ellison, N.B., Lampe, C. Lenhart, A. \& Madden, M. (2015a). 
Demographics of key social networking platforms. Pew Research Internet Project. Retrieved from http://www.pewinternet.org/2015/01/09/demographicsof-key-social-networking-platforms-2/.

Duggan, M., Ellison, N.B., Lampe, C. Lenhart, A. \& Madden, M. (2015b, Jan 9). Frequency of social media use. Pew Research Internet Project. Retrieved from http://www.pewinternet.org/2015/01/09/frequency-of-social-media-use-2/ .

Gibbs, A. (1997). Focus Groups. Social Research Update, 19. Retrieved from http://sru.soc.surrey.ac.uk/SRU19.html.

Greysen, R.S., Kind, T., \& Chretien, K.C. (2010). Online professionalism and the mirror of social media. Journal of General Internal Medicine, 25(11), 12271229.

HINTS (Heads of Interpreting Services). (2011). Declaration on the use of social media. 7 October 2011. Unpublished circular. Retrieved from https://aiic.net/ page/attachment/515.

Judd, J. (2015, Jun 8). Interpreters and social media. Auslan Stage Left. Retrieved from http://blog.auslanstageleft.com.au/2015/06/interpreters-and-social-media/.

Kaczmarczyk, J.M., Chuang, A., Dugoff, L., Abbott, J.F., Cullimore, A.J., Dalrymple, J., \& Casey, P.M. (2013). E-professionalism: A new frontier in medical education. Teaching \& Learning in Medicine, 25(2), 165. doi: 10.1080/10401334.2013.770741.

Lagenfeld, S.J., Cook, G., Sudbeck, C., Luers, T., \& Schenarts, P.J. (2014). 2014 APDS spring meeting: An assessment of unprofessional behavior among surgical residents on Facebook: A warning of the dangers of social media. Journal of Surgical Education, 71, e28-e32. doi:10.1016/j.jusrg.2014.05.013.

Lannin, D.G. \& Scott, A.N. (2013). Social networking ethics: Developing best practices for the small new world. Professional Psychology: Research and Practice, 44(3), 135-141.

Lawson, C. \& Cowling, C. (2015). Social media: The next frontier for professional development in radiography. Radiography, 21(2), e74-e80.

Lee, K. \& Ho, M. (2011). Online social networking versus medical professionalism. Medical Education, 45, 523.

Lewis, J. \& West, A. (2009). 'Friending': London-based undergraduates' experience on Facebook. New Media \& Society, 11(7), 1209-1229. doi: $10.1177 / 1461444809342058$.

Mazer, J.P., Murphy, R.E. \& Simonds, C.J. (2009). The effects of teacher selfdisclosure via Facebook on teacher credibility. Learning, Media and Technology, 34(2), 175-183. doi: 10.1080/17439880902923655.

Napier, J. \& Hale, S. (2013). Research methods in interpreting: A practical source. London: Bloomsbury.

Ollier-Malaterre, A., Rothbard, N. P., \& Berg, J. M. (2013). When worlds collide in cyberspace: How boundary work in online social networks impacts professional relationships. Academy of Management Review, 38(4), 645-669.

Ponce, B. A., Determann, J. R., Boohaker, H. A., Sheppard, E., McGwin Jr., G., \& Theiss, S. (2013). Social networking profiles and professionalism issues in residency applicants: An original study-cohort study. Journal of Surgical Education, 70(4), 502-507. doi: 10.1016i.jsurg.2013.02.005

Rabiee. F. (2004). Focus group interview and data analysis. Proceedings of the Nutrition Society, 63, 655-660. doi: 10.1079/PNS2004399

Ramarajan, L., \& Reid, E. (2013). Shattering the myth of separate worlds: Negotiating nonwork identities at work. Academy of Management Review, 38(4), 621-644.

Spector, N.D., Matz, P.S., Levine, J.L, Gargiulo, K.A., McDonald, M.B., \& McGregor, R.S. (2010). E-professionalism: Challenges in the age of information. Journal of Pediatrics, 156(3), 345- 346.

Statista. (2015). Number of monthly active Facebook users worldwide as of 1st quarter 2015 (in millions). Retrieved from http://www.statista.com/statistics/ 264810/number-of- monthly-active-facebook-users-worldwide/.

Stewart, D.W., Shamdasani, P.N., \& Rook, D.W. (2006). Focus groups: Theory and practice (2nd ed.). Los Angeles: Sage Publications. Retrieved from http://www.sagepub.com/sites/default/files/upmbinaries/11007_Chapter_7.pdf.

Utz, S. (2014). The function of self-disclosure on social network sites: Not only intimate, but also positive and entertaining self-disclosures increase the feeling of connection. Computers in Human Behaviour, 45, 1-10.

Walton, J.M., White, J. \& Ross, S. (2015). What's on YOUR Facebook profile? 
Evaluation of an educational intervention to promote appropriate use of privacy settings by medical students on social networking sites. Medical Education Online, 20, 28708. doi:10.3402/meo.v20.28708.

WASLI (2016). Your responses. WALSI Newsletter, 2. Retrieved from http://wasli.org/cat_news/wasli-newsletter-2016-2.

Weber, Z.A. \& Vincent, A.H. (2014). Research: Facebook as a method to promote a mindset of continual learning in an ambulatory care pharmacy elective course. Currents in Pharmacy Teaching and Learning, 6(4), 478-472.

Wendorf, J.E. \& Yang, F. (2015). Benefits of a negative post: Effects of computermediated venting on relationship maintenance. Computers in Human Behavior, 52, 271-277. doi: 10.1016j.chb.2015.05.040

Wesch, M. (2008, July 31). Context collapse. Mediated Cultures. Digital Ethnography (a) Kansas State University. Retrieved from: http://mediatedcultures.net/youtube/ context-collapse/.

Wilson, R.E., Gosling, S.D., Graham, L.T. (2012). A review of facebook research in the social sciences. Perspectives on Psychological Science, 7(3) 203-220. doi: $10.1177 / 1745691612442904$. 